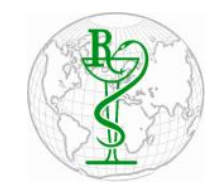

INDO GLOBAL JOURNAL OF

PHARMACEUTICAL SCIENCES

ISSN 2249- 1023

\title{
Formulation Development \& Evaluation of Microsphere of Garcinia Extract (Garcinia combogia)
}

\author{
Sharma R.K. ${ }^{1 *}$, Sharma A. ${ }^{1}$, Katara, A. ${ }^{2}$ \\ ${ }^{1}$ Mahatma Gandhi College of Pharmaceutical Sciences, Jaipur, Rajasthan, India \\ ${ }^{2}$ Analytical Division, Ayushraj Enterprise (P) Ltd., Jaipur, Rajasthan, India
}

\begin{abstract}
Address for Correspondance Sharma R.K., $\underline{\text { Rakeshkumarshar }}$ ma86@gmail.co

$\underline{\mathrm{m}}$
\end{abstract}

\section{Keywords}

Garcinia Extract; FTIR;

Microsphere; Thermal CrossLinking; Glutaraldehyde Cross Linking.

\begin{abstract}
Garcinia combogia, also known as Kokum butter tree and brindonia tallow tree. Fruit of Garcinia mainly contains hydroxy citric acid i.e. well known Antiobesity drug. Hydroxy citric acid naturally obtained and extracted from Garcinia combogia in form of calcium salt as powder is used in direct formulations. Microspheres are small spherical particles, with diameters in the micrometer range (typically 1 $\mu \mathrm{m}$ to $1000 \mu \mathrm{m})$. In present study, Garcinia microspheres are prepared by using Garcinia extract $(69 \%$, hydroxy citric acid). Two different methods were used for microsphere preparation i.e. Thermal cross-linking and Glutaraldehyde crosses linking. Microsphere prepared and evaluated by SEM analysis for particle size and FTIR for the identification of drug. Particle size obtained from first method was found $200-300 \mu \mathrm{m}$ while second method 50-200 $\mu \mathrm{m}$. FTIR scanning confirm the presence of Hydroxy citric acid in developed formulations.@ 2015 iGlobal Research and Publishing Foundation. All rights reserved.
\end{abstract}

\section{INTRODUCTION}

Microspheres are small spherical particles, with diameters in the micrometer range (typically $1 \mu \mathrm{m}$ to $1000 \mu \mathrm{m})$. Microspheres are characteristically free flowing powders consisting of proteins or synthetic polymers which are biodegradable in nature and ideally having a particle size less than $200 \mu \mathrm{m}$ [1].

Microspheres vary widely in quality, sphericity, uniformity of particle and particle size distribution. The appropriate microsphere needs to be chosen for each unique application [2]. The range of techniques for the preparation of microspheres offers a variety of opportunities to control aspects of drug administration. This approach facilitates the accurate delivery of small quantity of the potent drugs, reduced drug concentration at the site other than the target site and the protection of the labile compound before and after the administration and prior to appearance at the site of action.

Chitosan and cellulose were used as examples of fibers with high, intermediate and low bile acid-binding capacities, respectively. Chitosan polymer is used to increase the stability of the drug in which the drug is complexed with chitosan and make slurry and kneading for 45 minutes until dough mass. This dough mass is pass through sieve no.16 and make a granules is completely stable at different condition [3].

Novel drug delivery system is advantageous in delivering the herbal drug at optimum rate and delivery of drug at the site of action which minimizes the toxicity and enhances bioavailability of the drugs. 
Indo Global Journal of Pharmaceutical Sciences, 2016; 6(1): 14-17

Garcinia combogia, Garcinia Extract (Hydroxy Citric Acid)

Garcinia also known as Kokum butter tree, brindonia tallow tree [4]. The tree grows up to 10-18 meters with drooping branches. The tree is found in tropical rain forests of Western Ghats, from Konkan southwards. Garcinia extract i.e. processed by Garcinia fruit, containing NLT 50\% of Hydroxy Citric acid-Calcium Salt (HCA) figure- 01[5,6].

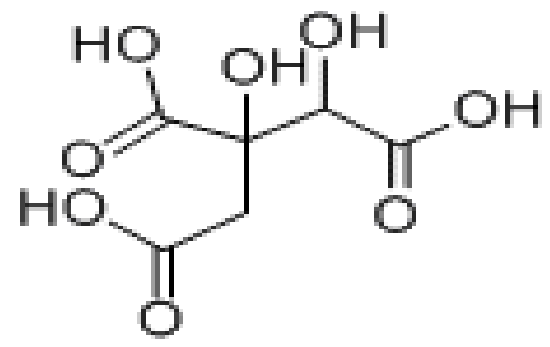

HYDROXY CITRIC ACID (GARCINIA EXTRACT) 1,2-Dihydroxy-1,2,3-propanetricarboxylic acid

\section{Figure-01}

Hydroxycitric acid appears to be a competitive inhibitor of the enzyme adenosine triphosphate-citrate (pro-3S)-lyase (a shorter designation is ATP Citrate Lysase), which is an enzyme in the biosynthetic pathway of fatty acids (de novo lipogenesis) and its inhibition results in suppressed formation of Acetyl-CoA from Citrate and less substrate for fatty acid synthesis in vitro. The (+)- isomer of Hydroxycitric acid does not have this same inhibitory potential, and is instead a substrate of the enzyme[7,8,9].

\section{MATERIALS \& METHODS}

Drug content Hydroxy citric acid calcium salt is received as a gift sample from Ayushraj enterprises (P) Ltd and Chitosan received from Veronica herbals. Other important chemicals such as Isopropyl alcohol, n-hexane, Light liquid paraffin, Heavy liquid paraffin, Span 85, Petroleum ether, Glacial acetic acid and Glutaraldehyde are procured form Merck and SD finechem.

\section{Preparation of Microspheres by Thermal cross- linking}

Citric acid, as a cross-linking agent was added to $30 \mathrm{ml}$ of an aqueous acetic acid solution of chitosan $(2.5 \% \mathrm{wt} / \mathrm{vol})$ maintaining a constant molar ratio between chitosan and citric acid (6.90 × 10-3 mol chitosan: 1 mol citric acid). The chitosan cross-linker solution was cooled to $0^{\circ} \mathrm{C}$ and then added to $25 \mathrm{~mL}$ of corn oil 2 minutes. This emulsion was then added to $175 \mathrm{~mL}$ of corn oil maintained at $120^{\circ} \mathrm{C}$, and cross-linking was performed in a glass beaker. Under vigorous stirring (1000 rpm) for 40 minutes. The microspheres obtained were filtered and then washed with diethyl ether, dried, and sieved [10].
Preparation of Microspheres by Glutaraldehyde crosses linking

A $2.5 \%(\mathrm{w} / \mathrm{v})$ chitosan solution in aqueous acetic acid was prepared. This dispersed phase was added to continuous phase $(125 \mathrm{~mL})$ consisting of light liquid paraffin and heavy liquid paraffin in the ratio of $1: 1$ containing $0.5 \%$ (wt/ vol) Span 85 to form a water in oil (w/ o) emulsion. Stirring was continued at $2000 \mathrm{rpm}$ using a 3- blade propeller stirrer). A drop-by-drop solution of a measured quantity $(2.5 \mathrm{~mL}$ each) of aqueous glutaraldehyde $(25 \% \mathrm{v} / \mathrm{v})$ was added at $15,30,45$, and 60 minutes. Stirring was continued for 2.5 hours and separated by filtration under vacuum and washed, first with petroleum ether $\left(60^{\circ} \mathrm{C}-80^{\circ} \mathrm{C}\right)$ and then with distilled water to remove the adhered liquid paraffin and glutaraldehyde respectively. The microspheres were then finally dried in vacuum desiccators [10].

\section{FTIR}

FTIR scanning performed by using the pressed pallete technique, drug pallete is prepared by mixing with $\mathrm{KBr}$ and followed to compress in hydraulic press.

Fourier transform infrared spectroscopy (FTIR) is a technique which is used to obtain an infrared spectrum of absorption, emission, photoconductivity or Raman scattering of a solid, liquid or gas. The term Fourier transform infrared spectroscopy originates from the fact that a Fourier transform (a mathematical process) is required to convert the raw data into the actual spectrum. The FTIR provides information about the surface composition of the microspheres depending upon manufacturing procedures and conditions [11].

\section{Scanning Electron Microscopy}

The most widely used procedures to visualize micro particles are conventional light microscopy (LM) and scanning electron microscopy (SEM). Both can be used to determine the shape and outer structure of micro particles. LM provides a control over coating parameters in case of double walled microspheres. The microspheres structures can be visualized before and after coating and the change can be measured microscopically. SEM provides higher resolution in contrast to the LM. SEM allows investigations of the microspheres surfaces and after particles are cross-sectioned, it can also be used for the investigation of double walled systems [11].

SEM of the Garacinia extract cal. salt microsphere was performed by scanning electron microscope. The samples were prepared by lightly sprinkling the microspheres powder on a double side adhesive tape which already shucked to on 
Indo Global Journal of Pharmaceutical Sciences, 2016; 6(1): 14-17

aluminum stubs.

The stubs were then placed into fine coat ion sputter for gold coating. After gold coating samples were randomly scanned for particle size and surface morphology $[12,13]$

\section{RESULTS \& DISCUSSION}

In present study we have concluded that drug is very much stable with developed formulation of microspheres. Microspheres have been easily prepared and evaluated for particle size and identification.

\section{FTIR Spectroscopy}

FTIR spectra possess six major valleys, observed in all samples (Fig. 1-3) showing the presence of hydroxyl group, ether group, acetic group, $\mathrm{C}-\mathrm{H}$ Bond. (Table 1)

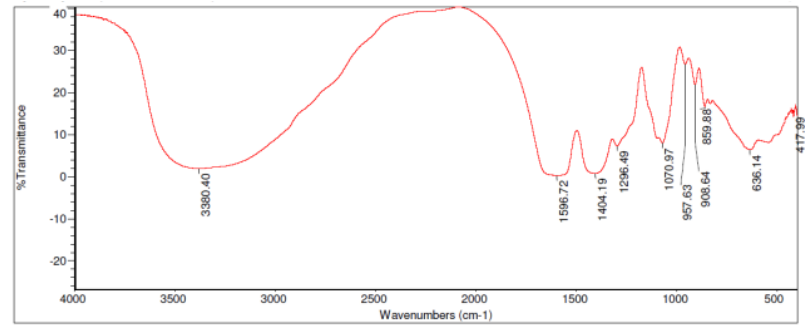

Figure 1- Garcinia dry extract-GR1

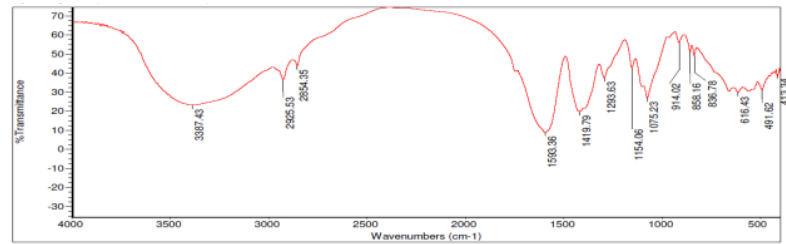

Figure 2- Garcinia Microsphere-GM2

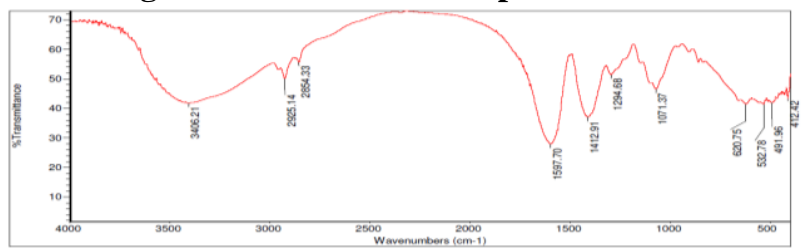

Figure 3- Garcinia Microsphere-GM3

Table 1. Wave number of Functional Groups Observed in I.R. Spectra of Compatibility Studies

\begin{tabular}{|l|l|l|l|l|}
\hline \multirow{2}{*}{$\begin{array}{l}\text { Sr. } \\
\text { no. }\end{array}$} & \multirow{2}{*}{ I.R. Spectra } & \multicolumn{3}{|c|}{$\begin{array}{l}\text { Valleys of Functional Group } \\
\text { Wavelength }\left(\mathbf{c m}^{-1}\right)\end{array}$} \\
\cline { 3 - 5 } & & GR1 & GM2 & GM3 \\
\hline$(1)$ & OH group & 3380.40 & 3387.43 & 3406.21 \\
\hline$(2)$ & Ether group & 1070.92 & 1075.23 & 1071.37 \\
\hline$(3)$ & Acid group & 1596 & 1593 & 1597 \\
\hline$(4)$ & C-H Bond & 859.88 & 858.16 & 857.14 \\
\hline
\end{tabular}

\section{Scanning Electron Microscopy (Particle size and shape)}

The particle size of different microsphere was observed from Scanning Electron Microscopy (Fig 4-6). The Garcinia Dry extract (GR1) particle size ranged from 300-500 $\mu \mathrm{m}$, Garcinia Microsphere Formulation 1 (GM2) particle size ranged from 200-300 $\mu \mathrm{m}$ while Garcinia Microsphere Formulation 2 (GM3) having particle size of 50-200 $\mu \mathrm{m}$ (Table 2).

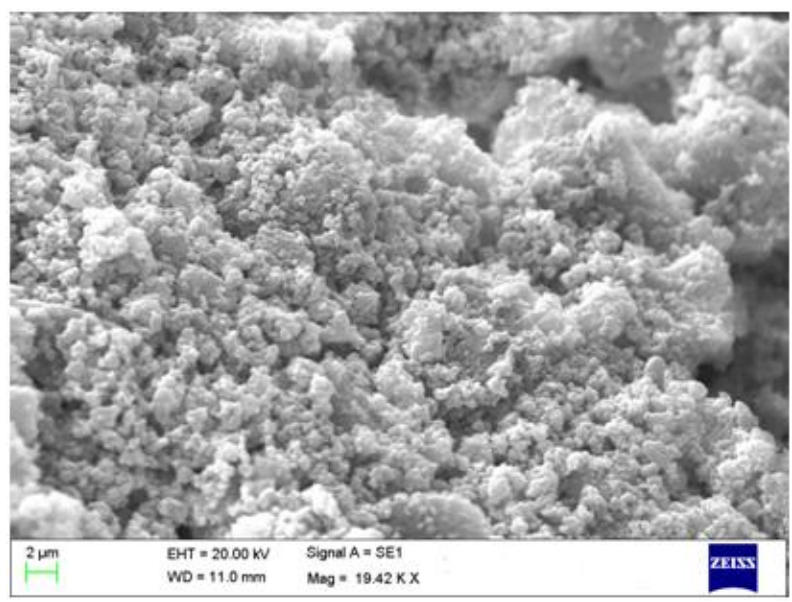

Figure 4- Garcinia Microspheres-GR1

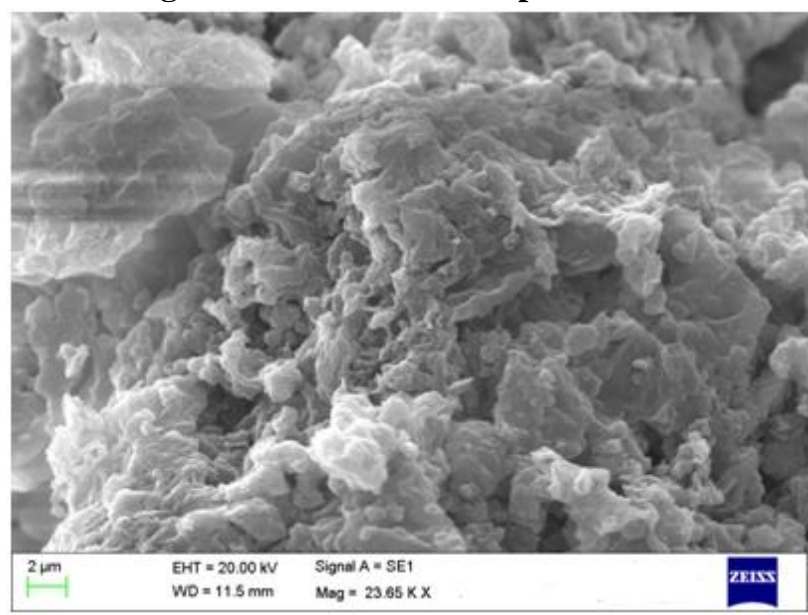

Figure 5- Garcinia Microspheres-GM2

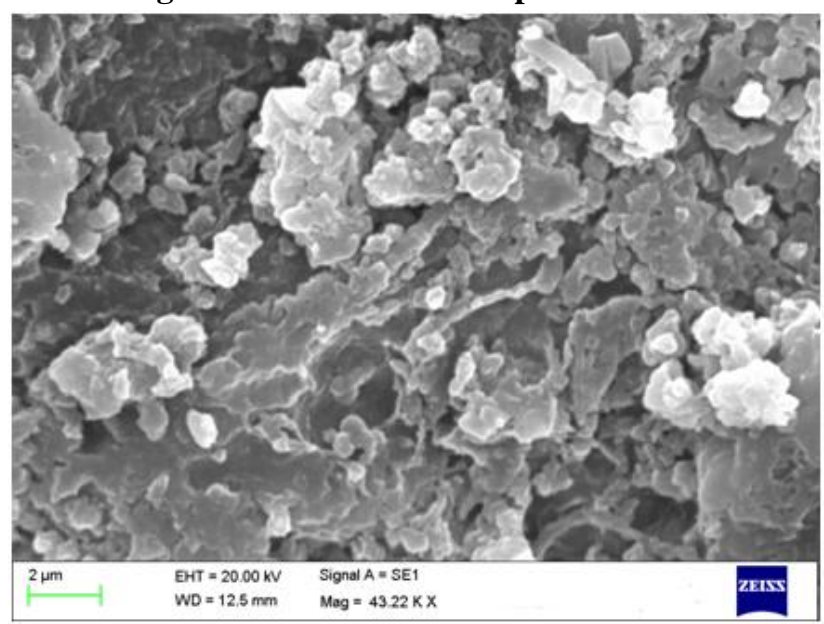

Figure 6- Garcinia Microspheres-GM3 
Indo Global Journal of Pharmaceutical Sciences, 2016; 6(1): 14-17

Table 2. Ranges of Particle Size observed from SEM analysis

\begin{tabular}{|c|c|c|c|}
\hline $\begin{array}{l}\text { S. } \\
\text { No }\end{array}$ & SAMPLE NAME & $\begin{array}{l}\text { SAMPLE } \\
\text { CODE }\end{array}$ & $\begin{array}{l}\text { PARTICLE } \\
\text { SIZE RANGE } \\
(\mu \mathrm{m})\end{array}$ \\
\hline 1 & $\begin{array}{ll}\text { Garcinia } & \text { Dry } \\
\text { Extract } & \end{array}$ & GR1 & $300-500$ \\
\hline 2 & $\begin{array}{l}\text { Garcinia } \\
\text { Microsphere, } \\
\text { Formulation } 1\end{array}$ & GM2 & $200-300$ \\
\hline 3 & $\begin{array}{l}\text { Garcinia } \\
\text { Microsphere, } \\
\text { Formulation } 2\end{array}$ & GM3 & $50-200$ \\
\hline
\end{tabular}

\section{CONCLUSION}

The chitosan microspheres of Garcinia were successfully prepared by glutaraldehyde cross linking method and confirmed that it is a best method to prepare Garcinia loaded microspheres from its higher percentage yield and basis of discrete, round and stable shape. The formulation GM2 \& GM3 has confirmed the drug content followed by FTIR analysis. The particle size of microspheres were determined by scanning electron microscopy and gives the particle size with in limit of microspheres and show uniform size of distribution. The average particle size was found to be in the range of $50-2000 \mu \mathrm{m}$. The prepared microspheres had good spherical geometry with smooth as evidenced by the scanning electron microscopy. Garcinia extract based microspheres are developed and evaluated for the first time. This whole study confirms that herbal based drug material can be easily used to prepare the novel formulation development concept as microspheres.

\section{ACKNOWLEDGEMENT}

Author is thankful for help and support provided by the Principle, Mahatma Gandhi College of Pharmaceutical sciences, Jaipur. Also gratitude to Analytical division, Ayushraj Enterprises pvt ltd, Jaipur for conducting the experimental protocol.

\section{REFERENCES}

1. Agusundaram, M., Chetty, M.S. Microsphere as A Novel Drug Delivery System A Review. International Journal of ChemTech Research. 2009; 1(3): 526-534.

2. Thanoo, B.C., Sunny, M.C., Jayakrishnan, A. Cross-linked chitosan microspheres: Preparation and evaluation as a matrix for the controlled release of pharmaceuticals. J Pharm Pharmacol. 1992; 44: 283-286.

3. Kalyan, S., Sharma, P.K. Recent Advancement In Chitosan Best Formulation And Its Pharmaceutical Application. Pelagia Research Library. 2010; 1(3):195-210.

4. Publications \& Information Directorate, Council of Scientific \& Industrial Research, G. combogia Desr. The Useful Plants of India, New Delhi, 1986.

5. Darji K.K., Shetgiri P., D'mello P.M., Evaluation of antioxidant and antihyperlipidemic activity of extract of Garcinia indica. Int J Pharm Sci Res 2010; 1 (12): 175-81.

6. Preuss H.G., Bagchi D., Bagchi M., Rao C.V.S., Satyanarayana S., Dey D.K., Efficacy of a novel, natural extract of (-)-hydroxycitric acid (HCA- SX) and a combination of HCA-SX, niacin-bound chromium and Gymnema sylvestre extract in weight management in human volunteers: a pilot study. Nutr Res 2004; 24.

7. Watson J.A., Lowenstein J.M., Citrate and the conversion of carbohydrate into fat, Fatty acid synthesis by a combination of cytoplasm and mitochondria. J Biol Chem., 1970.

8. Lowenstein, J.M., Effect of (-)-hydroxycitrate on fatty acid synthesis by rat liver in vivo. J Biol Chem., 1971.

9. Atmakuri, L.R., Dathi, S., Current Trends In Herbal Medicines. J Pharm Res. 2010; 3(1):109-113.

10. Nair, R., Reddy, B., Application of chitosan microspheres as drug Carriers: a review, Journal of Pharmaceutical Sciences and Research. 2009; 1(2):1-12.

11. Agusundaram, M., Chetty, M.S., Microsphere as a Novel Drug Delivery System A Review. International Journal of ChemTech Research. 2009;1(3):526-534.

12. Shovarani, K.N. and Goundalkar, A.G., Preparation and evaluation of microsphere of diclofenac sodium. Indian $\mathrm{J}$ Pharm Sci. 1994; 56(4): 45-50.

13. Ghosh, A, Nayak, UK and Roy, P. Development, evaluation and method selection for the preparation of lamivudine microspheres. The International J Pharmacy. 2007; 6(1):5257.

Indo Global Journal of Pharmaceutical Sciences( ISSN 22491023 ; CODEN- IGJPAI; NLM ID: 101610675) indexed and abstracted in EMBASE(Elsevier), SCIRUS(Elsevier),CABI, CAB Abstracts, Chemical Abstract Services(CAS), American Chemical Society(ACS), Index Copernicus, EBSCO, DOAJ, Google Scholar and many more. For further details, visit 